\title{
EVALUACIÓN DE LA CAPACIDAD ANTAGONISTA DE UN ANTIMICROBIANO PRODUCIDO POR Streptomyces sp CEPA $13 A-2$ FRENTE A MICROORGANISMOS RESISTENTES A B-LACTÁMICO DE ORIGEN HOSPITALARIO
}

\author{
Mirko Lino Navarro¹, Jorge León Quispe¹, Mónica Huamán Iturrizaga ${ }^{1,2}$
}

\begin{abstract}
RESUMEN
Objetivo. Evaluar la actividad antimicrobiana in vitro del actinomiceto marino cepa 13A-2 frente a enterobacterias productoras de $\beta$-lactamasas aisladas de pacientes con infecciones urinarias. Material y Métodos. Mediante la técnica de doble capa se selecciono el actinomiceto con la mayor actividad antagonista frente a 16 enterobacterias de los géneros Klebsiella sp., Proteus sp. y E. coli, productoras de betalactamasas de pacientes con infección urinaria del Instituto Materno Perinatal de Lima. La cepa 13-A2, aislada de una esponja marina colectada del litoral peruano, fue identificada molecularmente por amplificación del gen que codifica ARNr 16S La naturaleza peptídica del antimicrobiano se determinó mediante las técnicas de Bradford, Qubit fluoremeter, PAGE-SDS y HPLC. Se logró cuantificar la producción del antimicrobiano utilizando un nuevo medio de cultivo propuesto por el autor el cual fue comparado con caldo marino Resultados. El actinomiceto 13A2 fue identificado como Streptomyces sp. el cual inhibió todas las enterobacterias productoras de betalactamasas. En el nuevo caldo denominado ECOLINO 322 la actividad antibacteriana se ve maximizada en comparación al caldo marino. La cuantificación de proteínas indico la presencia de $15 \mathrm{mg} / \mathrm{mL}$ y la PAGE- SDS evidencio la presencia de 5 bandas con pesos moleculares entre 40 y $50 \mathrm{KDa}$. El análisis HPLC nos permitió confirmar la presencia de más de 4 compuestos con tendencia a la no polaridad. Conclusiones. Los actinomicetos marinos representan una fuente de metabolitos bioactivos que deben ser investigados para combatir la resistencia bacteriana de antibióticos betalactámicos.
\end{abstract}

\section{ASSESSMENT OF CAPACITY ANTAGONIST OF AN ANTIMICROBIAL PRODUCED BY Streptomyces SP CEPA 13A-2 FRONT RESISTANT MICROORGANISMS B-LACTAM HOSPITAL WASTE}

\begin{abstract}
Objective. To evaluate the in vitro antimicrobial activity of marine actinomycete strain $13 \mathrm{~A}-2$ against enterobacteria producing $\beta$-lactamases isolated from patients with urinary tract infections. Material and Methods. Using the technique of double layer actinomycete is selected with the highest antagonistic activity against 16 Enterobacteriaceae Klebsiella sp., Proteus sp. and E. coli, beta-lactamase-producing patients with urinary infection Maternal Perinatal Institute of Lima. The strain 13-A2, isolated from a marine sponge collected from the Peruvian coast, was identified molecularly by amplification of the gene encoding 16S rRNA the peptidic nature of the antimicrobial was determined by techniques Bradford, Qubit fluoremeter, SDS-PAGE and HPLC. It managed to quantify the production of antimicrobial using a new culture medium proposed by the author which was compared with marine broth. Results. Actinomycete 13-A2 was identified as Streptomyces sp. which he inhibited all lactamase producing Enterobacteriaceae. In the new called ECOLINO 322 broth antibacterial activity is maximized compared to the marine broth. Protein quantitation indicated the presence of $15 \mathrm{mg} / \mathrm{ml}$ and SDS-PAGE showed the presence of 5 bands with molecular weights between 40 and $50 \mathrm{KDa}$. HPLC analysis allowed us to confirm the presence of compounds with more than 4 tendency nonpolarity. Conclusions. Marine actinomycetes represent a source of bioactive metabolites that should be investigated to combat bacterial resistance to beta-lactam antibiotics.
\end{abstract}

Key words: Marine actinomycetes; B-lactam resistant; Antagonism; Streptomyces (Source: MeSH NLM).

\section{INTRODUCCIÓN}

A nivel mundial la resistencia antimicrobiana es un problema de salud que compromete la prevención y el tratamiento eficaz de las infecciones, causadas principalmente por las bacterias, constituye una amenaza creciente que se extiende a escala internacional ${ }^{1}$. El mecanismo de resistencia a los betalactámicos más común e importante, en las bacterias gramnegativas es la producción de enzimas betalactamasas, entre ellas la de espectro extendido (BLEE) que tienen la capacidad de hidrolizar y causar resistencia a penicilinas, cefalosporinas y monobactámicos, siendo inhibidas por el ácido clavulánico y las $\mathrm{AmpC}$ que no son inhibidas por el ácido clavulánico². Los microorganismos productores de BLEE pueden causar infecciones que presentan una elevada mortalidad. El tratamiento inadecuado de esas

${ }^{1}$ Universidad Nacional Mayor de San Marcos, Facultad de Ciencias Biológicas, Laboratorio de Ecología Microbiana. Lima, Perú.

${ }^{1,2}$ Instituto Nacional Materno Perinatal, Departamento de Patología, Servicio de Patología Clínica, Laboratorio de Microbiología. Lima, Perú. 
infecciones puede aumentar aún más la mortalidad. Una alternativa terapéutica para estos microorganismos son los antibióticos no betalactamicos y los carbapenemes. Sin embargo, la diseminación de los microorganismos productores de carbapenemasa (principalmente a causa de un deficiente control de infecciones) amenaza la utilidad a largo plazo de esta clase de fármacos. Es necesario desarrollar nuevos antibióticos que posean actividad frente a los microorganismos productores de BLEE ${ }^{3}$.

Por otro lado los microorganismos marinos como los actinomicetos se han convertido en un importante punto de estudio en la búsqueda de nuevos antimicrobianos. El océano cuenta con un enorme potencial para dar lugar a nuevas curas para enfermedades infecciosas, el descubrimiento de fármacos naturales de los océanos del mundo se ha acelerado por la singularidad química de los organismos marinos y por la necesidad de desarrollar nuevas alternativas de tratamiento para las infecciones difíciles de curar, debido a la gran resistencia de los microorganismos ${ }^{4-6}$. La presente investigación tiene por objetivo evaluar la actividad antimicrobiana in vitro del actinomiceto marino cepa 13A-2 (aislada de una esponja marina) frente a bacterias patógenas productoras de $\beta$-lactamasas aisladas de pacientes con infecciones urinarias y caracterizar preliminarmente los compuestos antimicrobianos.

\section{MATERIALES Y MÉTODOS}

Tipo de Estudio: se elaboró un estudio analítico, Observacional, prospectivo.

Población: Constituida por 27 actinomicetos antagonistas recuperados de invertebrados marinos (espongas calcareas, erizos y conchas de abanico) colectados del litoral peruano (Paracas, Mancora y Tumbes), Cepas Testigo, cepas de referencia de American Type Culture Collection (ATCC): Escherichia coli ATCC 25922 y Staphylococcus aureus ATCC 6538 y Enterobacterias (16) productoras de B Lactamasas aisladas de pacientes con infecciones urinarias en el Instituto Nacional Materno Perinatal.

\section{Metodología:}

1. Selección del mejor actinomiceto antagonista. El ensayo de antagonismo entre los 27 actinomicetos y las cepas de referencia ATCC, se realizó mediante el método de "doble capa" 7,8 . Se inoculó $50 \mu \mathrm{l}$ de cepas testigo (escala 0,5 de MacFarland) en $5 \mathrm{~mL}$ de caldo Tripticasa Soya semisólido ( $0,75 \%$ agar agar) después de una breve homogenización se agregó a modo de "segunda capa" sobre los cultivos del actinomiceto, se dejó solidificar 10 minutos y se incubó a $30^{\circ} \mathrm{C}$ por $24 \mathrm{~h}$. Al cabo de este tiempo se realizó las lecturas correspondientes mediante la medida de los halos de inhibición (diámetro en $\mathrm{mm}$ ).
2. Caracterización fenotípica y genotípica de la cepa seleccionada

2.1Se evaluó el crecimiento del microorganismo elegido sobre los medios Agar Marino, Agar Czapeck, Agar Winosgrasky, Agar Ashby y Agar Extracto de Levadura y Manitol (YEM) y el nuevo medio de cultivo, denominado medio ECOLINO 322.

2.2 Se evaluó la actividad degradativa sobre carbohidratos como: glucosa, sacarosa, galactosa, maltosa; la acción de diferentes aminoácidos como arginina, lisina, fenilalanina y triptófano, y la capacidad enzimática sobre sustratos como almidón $(10 \mathrm{~g} / \mathrm{L})$, Tween $80(10 \mathrm{~mL} / \mathrm{L})$, caseína $(100 \mathrm{~mL} / \mathrm{L})$, lecitina $(10 \mathrm{~g} / \mathrm{L})$, celulosa $(10 \mathrm{~g} / \mathrm{L})$, gelatina $(5 \mathrm{~g} / \mathrm{L})$ en el caso de DNA se evaluó con el medio DNase Test Agar w/Toluidine Blue. Las pruebas se realizaron por triplicado. Se utilizó la coloración Gram para la observación de esporas y estructuras miceliales.

2.3 EI ADN se extrajo utilizando un equipo comercial de purificación Wizard Genomics (Promega, Madison, EE.UU) siguiendo las instrucciones del fabricante. Mediante la Reacción en Cadena de la Polimerasa (PCR) se amplificó el gen que codifica ARNr 16S con un termociclador Multigene Gradient (Labet International INC., Woodbridge, NJ, EE.UU). Los productos de PCR se secuenciaron utilizando los servicios comerciales de Macrogen INC (Seúl, Corea). Las secuencias obtenidas se compararon con las depositadas en la Base de Datos del NCBI utilizando el programa BLAST (Basic Alignment Search Tool).

3. Pruebas de antagonismo del actinomiceto frente a enterobacterias productoras de $\beta$-lactamasas

La capacidad antagonista del actinomiceto seleccionado se realizó mediante la técnica de bicapa, enfrentándolo contra 16 enterobacterias productoras de $\beta$-lactamasas de espectro extendido provenientes de pacientes con infecciones urinarias en el Instituto Nacional Materno Perinatal.

\section{Caracterización de compuestos antibacterianos}

Para identificar el compuesto o metabolito productor del antibiótico el actinomiceto elegido se reproduce por un proceso fermentativo. En matraces de 100 $\mathrm{mL}$ se colocó $25 \mathrm{~mL}$ de Caldo Marino, inoculando la cepa en estudio y dejando a $250 \mathrm{rpm}$ durante $48 \mathrm{~h}$ (caldo iniciador o "estárter"). El proceso fermentativo se realizó en matraces de $500 \mathrm{~mL}$ conteniendo respectivamente Caldo Marino simple, Caldo Marino compuesto y el caldo ECOLINO 322. A cada medio se le adicionó $125 \mathrm{~mL}$ del caldo "starter". Este proceso fue evaluado durante 12 días a $250 \mathrm{rpm}$ de agitación y temperatura ambiente $\left(20-22^{\circ} \mathrm{C}\right.$ como promedio). 
Para saber si los sobrenadantes recuperados poseen actividad antibacteriana los cultivos fueron centrifugados a $5000 \mathrm{rpm}$ durante 25 minutos. La actividad antimicrobiana se evaluó mediante la prueba de pocillos, para lo cual los sobrenadantes fueron tamizados sobre gasa estéril y luego filtrados utilizando membranas y filtros Millipore, ambos de $0,45 \mu \mathrm{m}$ de porosidad. Estos sobrenadantes libres de células se guardaron en refrigeración $\left(4^{\circ} \mathrm{C}\right)$ para los ensayos posteriores ${ }^{9,10}$.

\section{a) Evaluación de proteínas}

Se determinó cualitativamente la presencia de proteínas en los sobrenadantes con actividad antimicrobiana mediante la técnica de Bradford siguiendo las recomendaciones de Álvarez ${ }^{11}$, se mezclaron $50 \mu \mathrm{L}$ de la solución de trabajo (sobrenadantes con actividad antimicrobiana) con $250 \mu \mathrm{L}$ del reactivo Bradford, se dejó reposar por 2 minutos y se evidenció cualitativamente la presencia de proteínas por la presencia de una coloración azulina. La cuantificación de proteínas se realizó mediante técnica colorimétrica utilizando el equipo Qubit Fluorometer (INVITROGEN) . Este equipo viene con un software incorporado que permite hacer la detección de absorbancia directamente. Esta prueba fue realizada en el laboratorio de Virología del Instituto Nacional de Salud (INS) sede Jesús María ${ }^{12}$.

La muestra tomada fue la que tenía 8 días de fermentación tanto en el Caldo Marino como en el medio ECOLINO 322. Se prepararon dos viales (eppendorf) agregando $190 \mu \mathrm{l}$ de buffer y $10 \mu \mathrm{l}$ del kit estándar. A otros cuatro eppendorf se tomó $180 \mu \mathrm{l}$ de buffer y se completó con $20 \mu \mathrm{l}$ de cada muestra, incluyendo los 2 caldos de 8 días de fermentación, uno de suero, como patrón negativo, y un control negativo.

b) Electroforesis en geles de poliacrilamidadodecil sulfato de sodio (PAGE-SDS)

Para cuantificar, comparar y caracterizar las proteínas se utilizó la técnica de elctroforesis. Los sobrenadantes de 8 días de fermentación fueron tratados a $100^{\circ} \mathrm{C}$ por $4 \mathrm{~min}$ con excepción de los 2 últimos carriles. La preparación del gel se realizó en condiciones reductoras (4 y 15\%) con SDS $0,1 \%$. Los voltajes fueron primero de $80 \mathrm{~V}$ por $10 \mathrm{~min}$ y luego a $160 \mathrm{~V}$ por $20 \mathrm{~min}$. El revelado se realizó utilizando 2 tinciones conocidas, en la primera se dejó por 60 minutos con el colorante Azul de Coomassie, luego se decoloró con la mezcla metanol-ácido acético, se dejó 15 minutos nuevamente con el colorante y finalmente se fija con ácido acético. En la segunda tinción se utilizó el colorante Nitrato de Plata, para esto previamente se fija el gel con ácido acético por 30 minutos y luego se agregó el nitrato de plata por 30 minutos.
Los marcadores fueron 6 , con pesos moleculares de $97,66,45,31,21$ y $14 \mathrm{KD}$. En cada carril se colocó $15 \mu \mathrm{l}$ de muestra, en el carril 1 se colocaron los patrones y a partir del 2 do al 10 mo carril se colocaron los sobrenadantes.

c) Caracterización de los antimicrobianos utilizando Cromatografía Líquida de Alta Resolución (HPLC).

Para caracterizar los antimicrobianos mediante HPLC fue necesario comprobar la actividad antimicrobiana de los sobrenadantes, el mismo que fue tamizado, centrifugado y filtrado; probando su actividad antimicrobiana de los días 3, 5 y 8 de fermentación. Esta actividad se realizó mediante técnica en pocillos. Después se procedió al análisis mediante HPLC Modelo ELITE LaChrom, con bombas de presión Hitachi L-2130. Se colocó $1 \mathrm{~mL}$ de las muestras en cada vial. Las condiciones fueron las siguientes: Columna fase reversa: Rp18; Temperatura columna: $25^{\circ} \mathrm{C}$, con volumen de inyección: $250 \mu \mathrm{L}$, proceso isocrático, fase móvil: Metanol HPLC, flujo: $1 \mathrm{~mL} / \mathrm{min}$, tiempo de corrida: 40 min y longitud de onda de detección: 254nm. Este ensayo se realizó en el laboratorio de Análisis Instrumental de Instituto del Mar del Perú IMARPE con sede en Callao.

\section{RESULTADOS}

1. Selección del mejor actinomiceto antagonista. De los 27 actinomicetos evaluados la cepa $13 \mathrm{~A}-2$ logró mayores porcentajes de inhibición contra $E$. coli ATCC 25922 , con actividades de hasta el $61 \%$ y contra la cepa testigo S. aureus ATCC 25923 el porcentaje de inhibición fue $74 \%$, siendo seleccionada para el presente estudio.

2. Caracterización fenotípica del actinomiceto 13A-2. El actinomiceto 13A-2 demostró ser Gram positivo con formación de abundantes hifas a partir del 4to día de crecimiento. La cepa seleccionada, pudo crecer en todos los medios de cultivo utilizados. Así, se evidenció un mejor desarrollo en los medios Marino, YEM y Ashby, donde se pudo observar colonias más consistentes y de mayor tamaño; en los medios TSA, Czapeck y Winogradsky y ECOLINO 322 el crecimiento fue moderado. Respecto al metabolismo sobre fuentes nitrogenadas, la cepa en estudio fue capaz de asimilar aminoácidos polares como lisina y arginina, sin embargo, en el caso de aminoácidos no polares como fenilalanina y triptófano, esta actividad no fue evidente. Además la cepa $13 \mathrm{~A}-2$ puede asimilar diferentes sustratos, demostrándose así su alta versatilidad bioquímica, puede degradar biopolímeros tales como péptidos, polisacáridos y aceites, produciendo amilasas, caseinasas, esterasas, colagenasas y lecitinasas. 


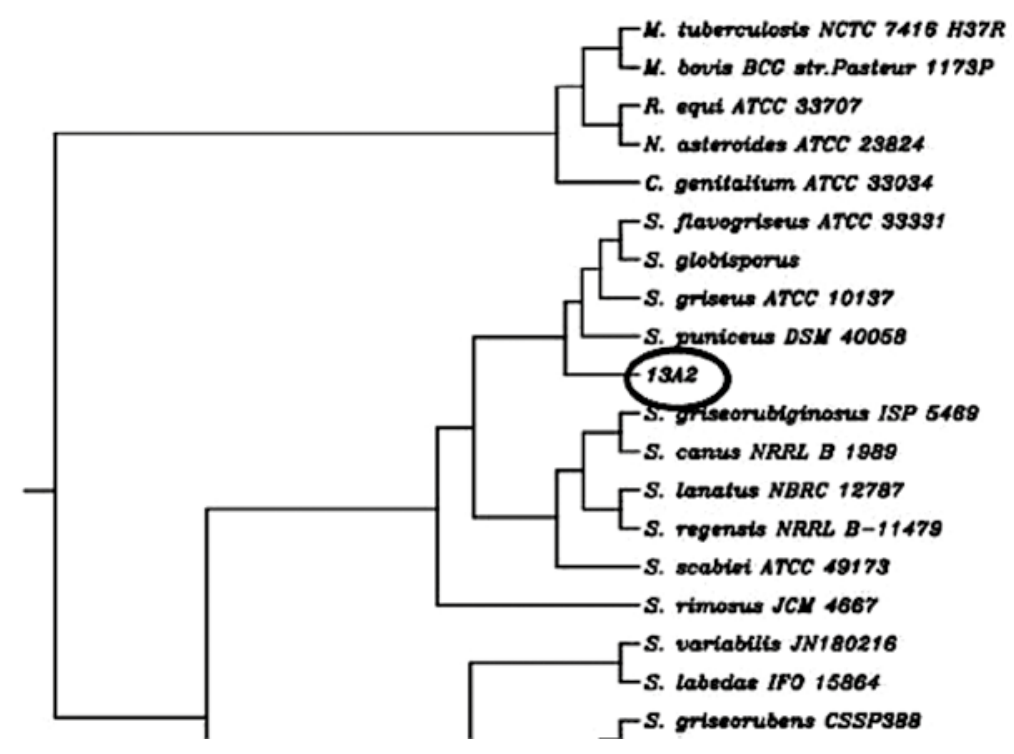

Figura 1. Árbol filogenético donde se resalta que la cepa en estudio pertenece al género Streptomyces; sin embargo, se trataría de una nueva especie no registrada hasta la actualidad.

Identificación genotípica de la cepa de actinomiceto13A-2.

Mediante la amplificación del gen que codifica ARNr 16 s y el posterior secuenciamiento nos arrojó que la cepa 13A-2 pertenece al género Streptomyces sp. y al parecer se trataría de una nueva especie.

\section{Pruebas de antagonismo de la cepa 13A-2 frente a} bacterias $\beta$-lactámico-resistentes

El actinomiceto 13A-2 mostró buena actividad antagonista contra las 16 cepas $\beta$-lactámicoresistentes, con halos de actividad que alcanzaron hasta $46 \mathrm{~mm}$ de diámetro en Agar Marino, siendo la cepa Klebsiella sp. BLEE que mostraron mayor resistencia a la inhibición. Sin embargo, estas mismas fueron inhibidas en mayor porcentaje cuando las evaluaciones se realizaron en el medio ECOLINO 322. Dicha mejoría fue notoria contra todas las cepas $\beta$-lactámico-resistentes; ya que en todas las pruebas los porcentajes de inhibición aumentaron desde unos pocos $12 \mathrm{~mm}$ en Agar Marino a unos $22 \mathrm{~mm}$ de diámetro en el medio ECOLINO 322.

Los porcentajes de inhibición evaluados mediante las pruebas de bicapa en el medio ECOLINO 322 superaron el $60 \%$ en todos los casos y en 10 de las 16 cepas enfrentadas; este porcentaje se elevó por encima del $75 \%$, llegando en algunos casos hasta el $84,2 \%$ de inhibición. En cambio, los resultados en Agar Marino fueron distintos, donde 15 de las 16 cepas resultaron con porcentajes menores o iguales al $50 \%$. Por esto se observó un mejor rendimiento en EcoLino 322 con un aumento de porcentajes por encima de $200 \%$ contra la cepa Klebsiella sp. BLEE. En el caso de las cepas $E$. coli BLEE mejoraron desde menores a $100 \%$ hasta mayores de $150 \%$. Se comprobó que las colonias del actinomiceto $13 \mathrm{~A}-2$ crecidas sobre el medio ECOLINO 322 tuvieron un tamaño igual o menor que en Medio Marino, sin embargo las actividades antimicrobianas fueron notoriamente mayores sobre el primer medio, por lo que los nutrientes presentes en este medio están influenciando positivamente la producción de antimicrobianos.

\begin{tabular}{|c|c|c|c|c|c|c|c|}
\hline & \multicolumn{3}{|c|}{ AGAR MARINO } & \multicolumn{3}{|c|}{ AGAR ECOUNO-322 } & \multirow[b]{2}{*}{$\begin{array}{l}\text { Wendimbento } \\
\text { (\$) }\end{array}$} \\
\hline Cepas Testigo & $\begin{array}{c}\text { colonis } \\
(\mathrm{mm})\end{array}$ & $\begin{array}{l}\text { Malo } \\
(\mathrm{mm})\end{array}$ & $\begin{array}{l}\text { Aatubiçón } \\
\text { [\$6] }\end{array}$ & $\begin{array}{c}\text { colonis } \\
(\mathrm{mm})\end{array}$ & $\begin{array}{l}\text { Malo } \\
(\mathrm{mm})\end{array}$ & $\begin{array}{c}\text { manisic. } \\
\text { (\$) }\end{array}$ & \\
\hline $\begin{array}{l}\text { E.coli ATCC } \\
29622\end{array}$ & 10 & 20 & 50 & 5 & 26 & 80,7 & 61.4 \\
\hline $\begin{array}{l}\text { "Se. oureus } \\
\text { ATCC } 25823\end{array}$ & 8 & 3s & 77,1 & 7 & 36 & 80,5 & 4,4 \\
\hline Ecol Butet & 8 & 13 & 38,4 & 6 & 38 & 84,2 & 119,2 \\
\hline Ecolis bute & 10 & 26 & 61.5 & 5 & 20 & 75 & 21.9 \\
\hline cons bute & 7 & 15 & 53,3 & 5 & 22 & 77,2 & 44,8 \\
\hline Ecoll bitet & 8 & 16 & So & 4 & 14 & 71,4 & 65,6 \\
\hline coal butet & 9 & 17 & 35,2 & 8 & 25 & 68 & 93,1 \\
\hline Ecol BLtet & 10 & 14 & 28,5 & 6 & 22 & 72,2 & 153,3 \\
\hline $\begin{array}{l}\text { Nebseriasp. } \\
\text { oute }\end{array}$ & 10 & 12 & 16 & 8 & 22 & 63,6 & 290,75 \\
\hline coal butet & 8 & 16 & 50 & 4 & 22 & 81,8 & 63.6 \\
\hline $\begin{array}{c}\text { Proteut ip. } \\
\text { Ampoc }\end{array}$ & 10 & 13 & 23 & 4 & 12 & 66,6 & 189,56 \\
\hline Ecolistert & 11 & 19 & 42,1 & 6 & 30 & 80 & 90 \\
\hline coal bute & 9 & 16 & 43,7 & 5 & 25 & 80 & 83 \\
\hline Ecal Butt & 9 & 14 & 35,7 & 5 & 25 & 80 & 124 \\
\hline cool Btre & 10 & 17 & 41,1 & 4 & 17 & 76,4 & 85,8 \\
\hline coal Butet & 11 & 15 & 26,6 & 5 & 25 & 80 & 200 \\
\hline Ecolis Bute & 10 & 20 & so & 6 & 23 & 73,9 & 47,8 \\
\hline Ecoll Butet & 9 & 15 & 40 & 8 & 46 & 82,6 & 106.5 \\
\hline
\end{tabular}

Figura 2. Porcentaje de inhibición comparativa de la actividad antagonista de la cepa $13 \mathrm{~A}-2$ contra $\beta$-lactámicoresistentes 


\section{Caracterización compuestos antibacterianos}

Después de los 12 días de fermentación de la cepa 13A-2 en los diferentes medios de cultivo se obtuvo que de los 3 caldos utilizados fue el Caldo Marino simple y el caldo ECOLINO 322 (nuevo) los que demostraron una mayor concentración de antimicrobianos a diferencia del Caldo Marino compuesto, siendo este último donde no se observó halos de actividad. Fue muy evidente esta actividad de los sobrenadantes contra las cepas referenciales E. coli 25922 ATCC y Staphylococcus aureus ATCC 25923, con una mayor inhibición sobre esta última cepa testigo.

La evaluación antimicrobiana de los sobrenadantes de la cepa $13 \mathrm{~A}-2$ frente a las 16 cepas testigo $\beta$-lactámico-resistentes de origen clínico arrojó resultados confirmatorios de las pruebas anteriores. Los resultados mostraron halos de inhibición mayores en las cepas E.coli BLEE en comparación con Proteus $s p$. Ampc y Klebsiella sp. BLEE, con halos de hasta $21 \mathrm{~mm}$ en el primer caso mientras que contra Proteus $s p$. Ampc fue de $15 \mathrm{~mm}$. Por otro lado, mediante la técnica en pocillos se confirmó que la producción de los antimicrobianos ocurren a partir del quinto día de fermentación. Esto es usando elcaldo ECOLINO 322 como medio de crecimiento de la cepa 13A-2.

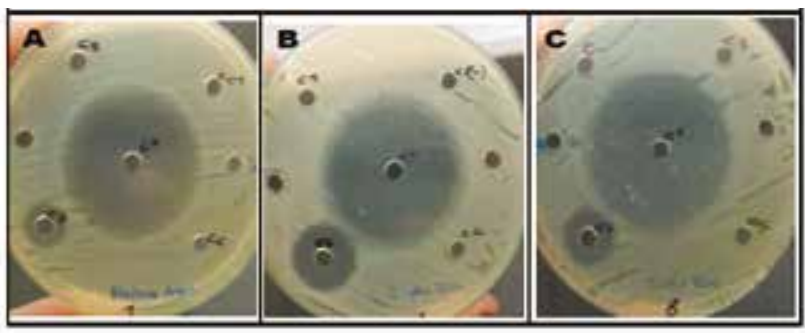

Figura 3. Comparación de la actividad antimicrobiana de los sobrenadantes de la cepa 13A-2 (flecha) contra $\beta$-lactámico resistentes. Halos de $14 \mathrm{~mm}$ contra Proteus sp. Amp C (A). Halos de $22 \mathrm{~mm}$ contra E. coli BLEE (B) y otra cepa $E$. coli BLEE (C) con halos de $17 \mathrm{~mm}$.

\section{Caracterización de compuestos antimicrobianos}

Con la selección del caldo marino simple y ECOLINO 322 como los mejores medios de fermentación para obtener actividad antimicrobiana considerable se procedió a evaluar dichos compuestos.

\section{A. Evaluación cualitativa y cuantitativa de proteínas}

Mediante la técnica de Bradford se pudo determinar cualitativamente la presencia de proteínas en los sobrenadantes de 5 y 8 días de fermentación, los cuales presentaban halos de inhibición, pero no en los sobrenadantes de 3 días, aquel que no presentó halos de inhibición, reforzando así la idea de que se trataría de compuestos antimicrobianos de naturaleza proteica. La cuantificación de péptidos en los sobrenadantes de 8 días con actividad antimicrobiana, es decir los que mostraron halos de inhibición, arrojó una concentración de $7 \mu \mathrm{g} / \mathrm{mL}$ de proteínas totales. Debido a que nuestro caldo en su forma natural presenta un color rojizo, este arroja un valor cuando se hace la lectura con Qubit fluorometer, aun cuando no tiene ningún día de fermentación, por ello el valor de concentración final se halló restando al sobrenadante en el tiempo de 8 días de fermentación, el valor obtenido del sobrenadante de 0 días.

B. Electroforesis en geles de poliacrilamidadodecil sulfato de sodio (PAGESDS)

Mediante PAGE-SDS se pudo apreciar la presencia de 5 bandas en el carril 10, que fue uno de los 2 carriles donde no hubo tratamiento con calor $\left(95^{\circ} \mathrm{C}\right)$. Los pesos moleculares de estas bandas se calcularon entre 40 y $50 \mathrm{KDa}$. El carril 10 nos permite diferenciar 2 bandas que se encuentran notoriamente definidas con respecto a las otras 3 que se ven muy tenues y las cuales no se aprecian en los carriles que se trataron con calor (del 1 al 8).

\section{Caracterización preliminar de los antimicrobianos utilizando cromatografía líquida de alta resolución (HPLC).}

Debido a que los extractos crudos obtenidos no presentaron actividad antimicrobiana como se ha demostrado en los ensayos mediante técnica de pocillos, se trabajó con los sobrenadantes ya que estos sí presentaron buena actividad tanto contra las cepas ATCC como contra las $\beta$-lactámico-resistentes; por lo tanto se realizó la caracterización de estos compuestos los cuales tenían el antecedente de presentar 5 péptidos en PAGE-SDS.

EI análisis HPLC nos permitió confirmar la presencia de más de 4 compuestos con tendencia a la no polaridad.A continuación se muestran los cromatogramas de cada sobrenadante evaluado.

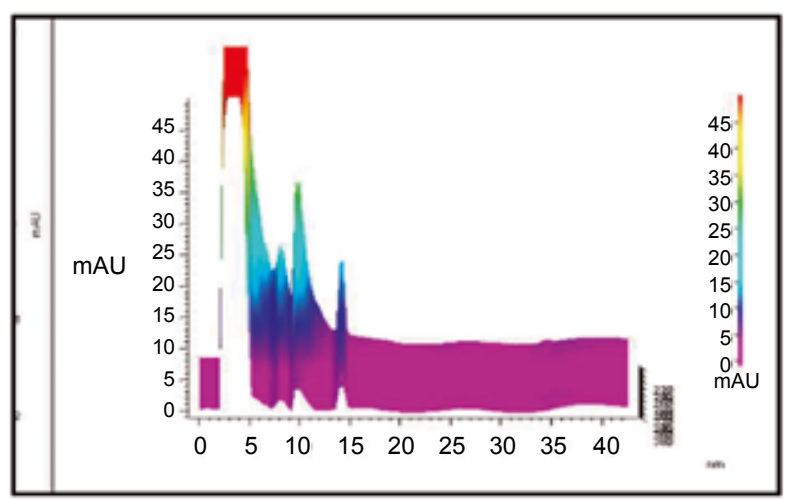

Figura 4. Cromatograma en $3 \mathrm{D}$ de los sobrenadantes de 8 días de fermentación. Los picos representan la cantidad de compuestos presentes en la muestra evaluada. 


\section{DISCUSIÓN}

Se evidenció gran actividad multienzimática tanto para degradar péptidos, polisacáridos y sustancias de naturaleza lipídica que se manifiesta en la capacidad de degradar los 6 sustratos evaluados deduciendo que nuestro actinomiceto secreta enzimas extracelulares tales como amilasas, proteasas, esterasas, Dnasas, lecitinasas. Esta actividad se justifica en el hecho que, la cepa en estudio ha sido aislada del interior de los tejidos de un invertebrado marino (esponja), donde bacterias de la flora normal tienen la capacidad de degradar las biomoléculas que ingresan como parte de su alimento, produciendo moléculas más simples, facilitándoles la absorción de nutrientes ${ }^{13}$. Esta actividad también la evidencio Mohan al comprobar la capacidad de los actinomicetos marinos para degradar almidón, caseína, lípidos y diferentes azúcares y aminoácidos, además de demostrar que sus cepas con mejor actividad antimicrobiana desarrollan mejor a temperaturas entre los $30^{\circ} \mathrm{C}$ y $40^{\circ} \mathrm{C}$ y $\mathrm{pH}$ entre 7,0 y 9,0 valores similares a los obtenidos en el presente estudio $^{14}$. La diferencia entre sus resultados y los nuestros es que los actinomicetos de su estudio degradaron el aminoácido no polar fenilalanina mientras que nuestra cepa seleccionada, no lo hizo, además en su estudio no se observó actividad celulolítica de su cepa como sí ocurrió en nuestras evaluaciones.

El análisis molecular nos permitió distinguir a nuestra cepa 13A-2 como Streptomyces sp. El árbol diseñado nos permite destacar que se trataría de una nueva especie no reportada hasta la actualidad con un elevado potencial biotecnológico como fuente productora de antibióticos de naturaleza peptídica que debe continuar estudiándose.

En cuanto a los medios de cultivo evaluados queda demostrado que el medio ECOLINO322 es un medio que potencia la actividad antimicrobiana de los actinomicetos cuando se realizan las pruebas de bicapa, en comparación con otros medios como el Agar Marino y el TSA. El fundamento que se utilizó para elaborar este nuevo medio es que la cantidad de nutrientes debe ser tal que no sólo permita el crecimiento de los actinomicetos sino que además permita llevarlos al estrés, el mismo que se presentó después de los primeros 3 días de crecimiento, cuando empezaron a agotarse los nutrientes y empezó la fase de diferenciación celular, es decir la formación de formas filamentosas y abundantes micelios. Esto se logró con una cantidad de nutrientes limitantes que provocó un estrés por falta de nutrientes lo cual permitió desencadenar señales para los actinomicetos en crecimiento y así activar los genes que participan en la síntesis de antibióticos. Al igual que en otros trabajos se ha comprobado que la síntesis de metabolitos secundarios coincide generalmente con el comienzo de la diferenciación morfológica y la formación del micelio aéreo, que según nuestros resultados lo podemos apreciar después del tercer día, y se hace muy notorio después de las $120 \mathrm{~h}$, al quinto día de la fase de crecimiento. Estos dos procesos muestran elementos comunes de regulación génica, regulación que está mediada por sustancias indicadoras que se producen durante la fase de diferenciación morfológica según lo ha comprobado Hopwood ${ }^{15}$.

Por otro lado se logró inhibir a todas las cepas patógenas con halos de hasta $22 \mathrm{~mm}$ para el caso de E. coli fenotipo BLEE mientras que la cepa Proteus $s p$. fenotipo ampC presentó menor sensibilidad con halos de $14 \mathrm{~mm}$, esto se debe probablemente a ciertos mecanismos de resistencia antimicrobiana que presenta un microorganismo, como lo demuestran diferentes investigaciones entre las que destaca Pazhanimurugan y colaboradores quienes obtuvieron diferentes halos de inhibición, con $14 \mathrm{~mm}$ para Escherichia coli y $12 \mathrm{~mm}$ contra Pseudomonas aeruginosa ambas cepas testigo de fenotipo $\beta$-lactámico resistentes de origen clínico ${ }^{16}$.

Los compuestos de naturaleza peptídica se iban concentrando a medida que los días de fermentación aumentaban coincidentemente con el aumento de la actividad antimicrobiana, por lo tanto se confirmó que los responsables de la actividad antimicrobiana tenían naturaleza proteica. Con el PAGE-SDS, se comprobó que los posibles péptidos responsables de la actividad antimicrobiana se encontraban con pesos moleculares entre 40 y $50 \mathrm{kD}$ que al compararlos con otros estudios resulta mejor que los obtenidos en otras investigaciones. Asha ${ }^{13}$ logró halos de inhibición de hasta $11 \mathrm{~mm}$ contra K. pneumoniae ATCC 27736 trabajando solo con sobrenadantes después del proceso fermentativo a concentraciones de $120 \mu \mathrm{g} / \mathrm{ml}$, si comparamos sus resultados con los del presente trabajo se puede observar que en nuestras pruebas se lograron halos de hasta $15 \mathrm{~mm}$ contra el mismo género de cepa testigo, pero que estos se obtuvieron con concentraciones muy inferiores, pues nuestros sobrenadantes poseen $7 \mu \mathrm{g} / \mathrm{ml}$ del principio activo, 17 veces menos concentrada que la de Asha y colaboradores y además, nuestros resultados fueron obtenidos contra cepas de fenotipo $\beta$-lactámico resistentes, lo cual demuestra la elevada potencia de nuestros antimicrobianos.

Antimicrobianos de naturaleza peptídica producidos por Streptomyces también han sido aislados y estudiados logrando identificar una proteína con actividad contra $E$. coli, cuyo peso molecular fue calculada en $39 \mathrm{KDa}$, algo cercano a los $45 \mathrm{KDa}$ que presentan las proteínas en nuestro PAGE-SDS ${ }^{17}$.

Analizando el PAGE-SDS algunos autores observaron antimicrobianos de naturaleza peptídica que no tienen el mismo blanco de acción, se propone que actúan a nivel de fosfolípidos de membrana, mientras que nuestros resultados sugieren que siendo de naturaleza anfipática, pueden interactuar sin dificultades con membranas plasmáticas y aprovechar esta capacidad para penetrar y actuar a nivel de pared bacteriana, la cual puede ser en primer lugar inhibiendo enzimas esenciales que participan 
en la formación del peptidoglucano o en segundo lugar rompiendo los enlaces tipo $\beta 1,4$ que mantienen unidas al Nacetil-murámico con el $\mathrm{N}$-acetil-glucosamina ${ }^{17,18}$

Este planteamiento teórico lo vemos reforzado por el hecho que la inhibición es mayor en microorganismo Gram positivos (St.aureus) que poseen mayor concentración de peptidoglucano. Por otro lado éstos microorganismos poseen naturalmente mecanismos para evadir la respuesta de antibióticos $\beta$-lactámicos por la producción de enzimas betalactamasa de espectro extendido y por ende son menos sensibles a la acción de nuestros péptidos. Otro resultado que refuerza nuestra teoría es que nuestro complejo antimicrobiano es capaz de degradar la celulosa, polisacárido que también posee enlaces tipo $\beta$ 1,4 y además dicha actividad coincide exactamente con la actividad antimicrobiana, es decir que actúan recién a las $108 \mathrm{~h}$ (cercano al quinto día) con lo cual las posibilidades de que se trate del mismo compuesto que actué a nivel de enlaces $\beta 1,4$ son mayores. Según los resultados obtenidos por HPLC con detector UV, nuestro antibiótico es un complejo antimicrobiano formado por varios compuestos, al igual como nos reveló PAGE-SDS demostrando que nuestro antimicrobiano está formado por proteínas de entre 40 y $50 \mathrm{KDa}$.

Aún falta conocer si este compuesto es sólo proteína o está formado por algunos grupos de diferentes naturalezas; para poder afirmar esto sería necesario un análisis más riguroso, por ejemplo utilizando HPLC acoplado a espectrómetro de masas y también utilizando Resonancia Magnético Nuclear (RMN). Por ahora según los materiales y técnicas utilizadas podemos afirmar que el antibiótico producido por la cepa marina Streptomyces sp.13A-2 que inhibió a las 16 bacterias $\beta$-lactámico resistentes de origen hospitalario es un complejo antimicrobiano de naturaleza peptídica.

A diferencia del trabajo de Ligia y colaboradores ${ }^{19}$ con los resultados obtenidos mediante PAGE-SDS $Y$ HPLC podemos afirmar que nuestro compuesto es un complejo antimicrobiano formado por varios péptidos y no solo uno como ellos concluyeron, esto puede explicar porque nuestro complejo tiene un mayor espectro de acción, inhibiendo a diferentes $\beta$-lactámicos resistentes Gram negativos como E. coli, Klebsiella sp y Proteus sp. y también a Gram positivos como Staphylococcus aureus ATCC 25923 aun cuando nuestro compuesto se encuentra a menor concentración. Esto se ve reforzado por Kanlayani ${ }^{17}$ quien obtuvo actividad antimicrobiana, tanto contra Gram positivos y Gram negativos excepto E.coli, a partir de sobrenadantes peptídicos.

Agradecimientos: Los autores agradecen al Vicerrectorado de Investigación (VRI) de la Universidad Nacional Mayor de San Marcos, Lima, Perú, por el financiamiento parcial de este estudio a través del Fondo de Fomento de Tesis de Grado de la Facultad de Ciencias Biológicas.

Al Laboratorio de Microbiología del Instituto Nacional Materno Perinatal por su colaboración en la identificación de los mecanismos de resistencia bacteriano.
Conflictos de interés: Los autores manifiestan no tener conflictos de intereses.

\section{REFERENCIAS BIBLIOGRÁFICAS}

1. Organismo Mundial de la Salud. Antimicrobial resistance. Global Report on Surveillance, 2014.

2. Sociedad Española de Enfermedades Infecciosas y Microbiología Clínica. Detección fenotípica de mecanismos de resistencia en gramnegativos. 2011.

3. Paterson D. Infecciones por microorganismos productores de betalactamasas de espectro extendido (BLEE): Un desafío epidemiológico y terapéutico. Enfe infec microbiol clin 2007;25(2):60-3

4. Fenical W. Chemical Studies of Marine Bacteria: Developing a New Resource, Chem Rev 1993;93: 1673-1683.

5. Jensen P, Fenical W. Strategies for the discovery of secondary metabolites from marine bacteria: Ecological perspectives. Ann. Rev. Microbiol 1994; 48:559-584.

6. Leiva S, García-Quintana H, Zaror L. Actinomycetes acuáticos: una revisión sobre su aislamiento, distribución y potencial antibiótico. Medio Ambiente 2000;13: 80-8

7. Westerdahl A, Olsson J, Kjelleberg S. Isolation and characterización of turbot (Scophthalmusmaximus) associated bacteria with inhibitory effects against Vibrio anguillarum. Appl Environ Microbiol 1991; 57(8):2223-2228

8. León J \& García-Tello P. Cepas nativas del bacterioneuston marino y su actividad inhibitoria de bacterias ictiopatógenas. Rev Per Biol 1998;5(1): 47-64

9. Mannangatti Krishnaraj and Narayanasamy Mathivanan. Diversity of marine actinomycetes in the Bay of Bengal and their antibacterial activity against human pathogens. J Mar Biol Ass India 2011; 53 (1): 135 - 138.

10. Peela , Kurada B,Terli R. Studies on antagonistic marine actinomycetes from Bay of Bengal.World Journal of Microbiology \&Biotecnology 2005; 21:583-585

11. Álvarez $\mathrm{S}$, Evelyn K. Producción de mRNA para citoquinas hematopoyéticas (IL-3, GM-CSF e IL-7) en ratones inmunosuprimidos tratados con extracto acuoso de Lepidium meyenii walpers (maca). Tesis para optar al Grado Académico de Magíster en biología molecular. Lima, Perú 2013.

12. Rojas C. Identificación de genes tipo péptido antimicrobiano provenientes de Solanumlycopersicumvar Cerasiforme.Tesis de maestria en Ciencias Bioquímicas Universidad Nacional de Colombia Facultad de Ciencias, 2010.

13. Nair A, Selvakumar D, Dhevendaran K. Occurrence of Sponges Associated Streptomyces and its Antimicrobial Activity Dept of Aquatic Biology and Fisheries, University of Kerala. Journal of Fish and Marine Sciences 2011; 3 (2): 151-158.

14. Mohan R, Ramasamy V. Isolation and characterization of marine antagonistic actinomycetes from west coast of india. Medicine and Biology 2008;15(1):13-19

15. Hopwood D. Towards an understanding of gene switching in Streptomyces, the basis of sporulation and antibiotic production. Proc R SocLond Biol Sci 1988; 235:121-138.

16. Groban ES, Clarke E, Salis HM, Miller SM, Voigt CA. Kinetic buffering of cross talk between bacterial two-component sensors. J Mol Biol 2009;390:380-93.

17. Kanlayani Charoensopharat, PetcharatThummabenjaponse, PisanSirithorn and Sompong Thammasiriak. Antibacterial substance produced by Streptomyces sp. N0 87. African Jourrnal of Biotechonology 2008;7(9):1362-1368.

18. Ligia L, Corrales G, Gelmy L, Ciro G. Péptidos con actividad antimicrobiana producidos por microorganismos nativos. Revista De la Facultad de Química Farmaceútica. Universidad de Antioquia, Medellin, Colombia 2010;17:181-190.

19. Gotoh Y, Eguchi Y, Watanabe T, Okamoto T, Doi A, Utsumi R. Two-component signal transduction as potential drug targets in pathogenic bacteria. CurrOpinMicrobiol 2010;13:232-9. 